\title{
Modeling the Acceptance and Use of Electronic Medical Records from Patients' Point of View: Evidence from Saudi Arabia
}

Dalal Bamufleh ( $\sim$ bamuflehd@rcyci.edu.sa )

Yanbu University College

Research article

Keywords: EMR, HIS, TAM, UTAUT

Posted Date: July 8th, 2020

DOI: https://doi.org/10.21203/rs.3.rs-36891/v1

License: (c) (i) This work is licensed under a Creative Commons Attribution 4.0 International License. Read Full License 


\section{Abstract \\ Background}

The employment of IT in healthcare reflects a need to meet the increasing demands of patients and to upgrade the quality and productivity of the provided services. However, the literature demonstrates many failures in systems and IT technology implementation in the context of healthcare. One of the reasons behind these failures is users' resistance to accept such new technology. The ministry of health in Saudi Arabia has prioritized the embracing of new technologies that could level up the healthcare service, such as the adoption of electronic medical record (EMR) systems. On the other hand, studies that address the acceptance and use of hospital information systems and EMRs in Saudi Arabia from patients' points of view are scarce. The aim of this study was to explore patients' acceptance of an EMR system by testing a proposed theoretical model adapted from the technology acceptance model (TAM) and the unified theory of acceptance and use of technology (UTAUT).

\section{Methods}

An online questionnaire was used where questions were based on the proposed model constructs (facilitating conditions, perceived ease of use, perceived usefulness, attitude, and behavioral intention). One hundred sixteen patients responded to the questionnaire. The model was then tested using the structural equation modeling method to identify the factors that affect patients' intention to use the online services of the EMR.

\section{Results}

The analysis of the research model suggested that (1) facilitating conditions that involved patients' knowledge, skills, and the provided support by the hospital directly influenced the degree of perceived ease of use (PEOU) of the system. (2) PEOU directly affected the EMR's perceived usefulness (PU). (3) PU directly affected patients' attitudes (ATT) toward using the EMR. (4) A positive effect is found between ATT and the behavioral intention to use EMR.

\section{Conclusion}

The study results have implications for healthcare IT acceptance research and efforts in Saudi Arabia, as to date patients' perspectives have received little attention. The research also makes a theoretical contribution as it validated the proposed model, which integrated constructs from TAM and UTAUT.

\section{Background}

The current utilization of information technology in healthcare stems from a need to deliver better healthcare and to meet patients' growing demands. Patients' demands have changed, and their expectations have increased, which requires upgrading the healthcare industry to meet such expectations. Primary patients' expectations include the 24/7 availability of medical services, accessibility to their electronic medical records (EMRs), effective and reliable online appointment systems, and reduced patient waiting times in doctors' offices (Meyers, 2003). One solution to overcome healthcare service issues in meeting patients' demand is to utilize information and communication technologies (ICT). ICT integration into the healthcare sector enables and facilitates the redesign of healthcare services in a way that satisfies patients' increasing demands (Lee et al., 2011). The implementation of IT/ICT in the healthcare context can be in one or more of the following forms: EMRs, electronic health records (EHRs), computerized physician order entry, clinical decision support systems (CDSS), mobile healthcare systems, and picture archiving and communication system (PACS) (Ahlan \& Ahmad, 2014; Aldosari, 2012; Aljarboa et al., 2019; Alsulame et al., 2016).

According to Lee et al. (2011), the hospital information system (HIS) is one of the primary forms of ICT integration in healthcare. A HIS is defined as "a comprehensive, integrated information system designed to manage the administrative, financial and clinical aspects of a hospital. It aims to achieve the best possible support of patient care and administration by electronic data processing" (Ismail et al., 2010, p. 16-24). A HIS can also be defined as "an information system that performs the function of processing data, 
information and knowledge in the secondary and tertiary healthcare levels" (Lee et al., 2011, p. 2129-2140). A HIS supports hospitals' management in making the right decisions by providing the needed information at the right time. It empowers hospitals to access, evaluate, and extract insights from healthcare data, which contribute to patient care and overall quality improvement (Ismail et al., 2010). The predictable core benefits for implementing HISs are quality improvement for healthcare services, price reduction, and reduction of medical errors (Fraser et al., 2005). In developing countries, HIS implementation provides an exceptional opportunity to leverage the quality of healthcare services, decrease healthcare costs, and improve productivity and resource utilization (Williams \& Boren, 2008).

According to Gell \& Gitter (2008), a HIS performs five key functions:

1. Clinical order entry. This function involves organizing and managing all medical services that a patient needs, such as examinations, admission and surgery appointments, and medical counseling. It is considered as the most crucial function of any HIS.

2. Scheduling. Because HIS is an integrated information system, it synchronizes all medical information in a timely and systematic manner in order to shorten patients' waiting time and enhance the quality of healthcare services.

3. Electronic patient record/ electronic medical record. This refers to the electronic collection of patient information during any interaction between that individual and the hospital. This includes patient medical history, examination results, clinic visit details, and billing information. Patients' records are stored in a much-secured way, so only authorized people can access, retrieve, and review them.

4. Structured reporting. As mentioned above, a HIS supports management in making decisions; it is an interactive reporting tool that replaces traditional paper reports. By using a database, the system is also capable of providing a visual presentation and illustration of data.

5. Process management. In addition to the benefits a HIS provides to improve medical services to patients, it helps in organizing and managing the administrative and business processes to deliver such services. A HIS provides the workload along with the required activities for each user according to his or her role. Also, a HIS shows the necessary procedures and steps required to deliver patient treatment.

One of the HIS elements that has received significant attention in HIS research is EMRs/EHRs. These are defined as "a longitudinal electronic record of patient health information generated by one or more encounters in any care delivery setting. Included in this information are patient demographics, progress notes, problems, medications, vital signs, past medical history, immunizations, laboratory data, and radiology reports. The EHR automates and streamlines the clinician's workflow. The EHR has the ability to generate a complete record of a clinical patient encounter-as well as supporting other care-related activities directly or indirectly via interface-including evidence-based decision support, quality management, and outcomes reporting" (HIMSS, n.d.). EHR systems enable hospitals to save and safeguard patients' current and historical information, and to provide patients with greater accessibility to their digital records through an online platform or mobile applications (Holden \& Karsh, 2010) (Table 1).

Due to the effective role of EMR systems in upgrading and enhancing health services quality, EMRs are considered as the core element of HIS and the healthcare infrastructure (Al-Sobhi et al., 2011; Chaudhry et al., 2006). A research study for identifying the benefits of implementing and using HISs and EMRs was conducted in four Saudi hospitals that fully employed these technologies. The study targeted doctors, nurses, technicians, and administrative staff who have experienced using HISs and EMRs. The study revealed the following 10 perceived benefits and advantages for implanting a HIS and EMR, ranked in descending order: "1) Improved information access, 2) Increased healthcare professionals productivity, 3) Improved efficiency and accuracy of coding and billing, 4) Improved quality of healthcare, 5) Improved clinical management (diagnosis and treatment), 6) Reduced expenses associated with paper medical records, 7) Reduced medical errors, 8) Improved patient safety, 9) Improved patient outcomes and 10) Improved patient satisfaction" (Khalifa, 2017). According to Bozaykut et al. (2016), there is high adoption and implementation of HISs in developed countries, which in return results in quality improvement in healthcare delivery and reduction in medical errors. At the same time, because of some challenges and barriers, the healthcare industry is progressing slowly in healthcare technology and HIS adoption and implementation (Anastassopoulos et al., 2012; Menachemi et al., 2004).

The ICT adoption and technology acceptance literature classifies the adoption challenges into three classes: organizational challenge/organizational characteristics, human challenge/individual characteristics, and technological challenge/technological

Page 3/25 
characteristics (Hu et al., 1999; Zakaria et al., 2010). In particular, the employment of such systems in developing countries involves numerous challenges and is still at the early stages (Alsharo et al., 2019). These challenges are mentioned in the literature around HIS adoption in developing countries and are mainly categorized into three categories: economic, such as high costs and limited and insufficient financing; technical, such as poor or inadequate infrastructure; and political challenges like wars and immigrants. Also, developing countries suffer from healthcare professionals' scarcity and limited access to advanced technologies (Ahlan \& Ahmad, 2014; Fraser et al., 2005). In fact, the extent of these challenges' effect on HIS implementation varies from one developing country to another, as they maintain different resources, populations, and market sizes (Ahlan \& Ahmad, 2014).

A study conducted by Almaiman et al. (2014) aimed to explore health information technology (HIT) implementation and to identify the main associated challenges with using electronic health applications (eHealth) in primary healthcare centers (PHCCs) in the Kingdom of Saudi Arabia. The data for the study was collected through academic search and interviewing IT personnel working in the National Guards for Health Affairs and the Ministry of Health and primary healthcare directors. The sample covered five areas of the kingdom: Riyadh, Hail, Arar, Rafha, and Najran. The findings showed that HIT adoption and use is growing in Saudi Arabia (SA), but it still is in its early stage. HISs at PHCCs in SA contributed to some advantages, such as lowering the "no-show rate" for patients who had booked appointments and improving service quality. The majority of PHCCs in SA maintain the basic required infrastructure for ICT and have the needed IT resources that include intranet and database resources. Despite this, the utilization of HISs and electronic health applications is below the potential use; for example, most services used through HISs at PHCCs in SA are booking appointments and updating users' information. This low utilization is due to reasons such as system failure, difficulty in using and navigating the online system, negative attitudes toward using the systems, and work overload (Almaiman et al., 2014).

Additionally, the study identified two critical challenges for HIS implementation in PHCCs. First, the distribution, implementation, and utilization of HISs varies between PHCCs located in cities and rural areas. Second, the majority of PHCCs in SA use EMRs along with paper-based medical records, which affects the quality of data (Almaiman et al., 2014). The same challenges were reported in another study on EMR use in SA (Al-Sobhi et al., 2011). Additionally, EMR implementation in SA has been met with further barriers such as policies, organizations' technical infrastructure, users' resistance to change, training, and costs. One study targeted 185 nurses across three public hospitals where the same EHR was implemented in the Eastern Province of SA; the study revealed some barriers in using the EHR system (ordered from most to least frequently cited): "loss of access to medical records transiently if computer crashes or power fails," "lack of continuous training/support from IT staff in the hospital," "additional time required for data entry (i.e., more workload)," "system hanging up problem," "complexity of technology," and "lack of customizability of the system according to users' needs" (El Mahalli, 2015).

Similarly, another study targeted 19 governmental hospitals located in the Eastern Province of SA that identified some challenges in EHR system implementation. These challenges were centered on doctors' and nurses' resistance and lack of seriousness in inserting the needed inputs to use system functions such as patient prescriptions, progress notes, and patient diagnoses (Bah et al., 2011). Furthermore, the confidentiality of patient information presents a considerable challenge for medical institutions in SA. Organizations that fail to keep patient information secure are subject to disciplinary actions from the Saudi Ministry of Health. Electronic medical services provided in Saudi hospitals are not unified and combined at the local or national levels, which results in data quality problems such as duplication, inconsistency, missing data, and inaccuracy. Such issues threaten data security and increase healthcare costs (Almaiman et al., 2014).

HIS implementation is a growing trend in developed countries, and many developing countries, including SA, are moving toward establishing and adopting one or more forms of HIS (Alsharo et al., 2019; El Mahalli, 2015). In spite of the benefits HISs provide to healthcare institutes in the developing countries, it doesn't assure users' adoption and acceptance (Esmaeilzadeh et al., 2015). At the same time, the HIS adoption literature shows that more than $50 \%$ of health information systems are not used because of factors such as the extensive time needed for digitizing patients' records, checking and evaluating HIS decisions, and users' refusal or resistance (Kilsdonk et al., 2010). The usefulness of any great technology can be measured by the number of uses and its employment in achieving its purposes. Thus, various technological barriers appear when users start interacting with the technology. Some of these barriers are issues relating to ease of use, usefulness, complexity, usability, output quality, compatibility, and observability. These technological challenges are studied through human-computer interaction. Also, user acceptance plays a major role in the successful adoption of healthcare IT solutions and systems (Aldosari, 2012; Alsharo et al., 2019). For these reasons, studying users' behavior toward using and accepting the system can improve the system implementation and performance

Page $4 / 25$ 
(Kilsdonk et al., 2010). The HIS adoption literature shows that many HIS implementations fail as a result of users' resistance or rejection (Kijsanayotin et al., 2009; Spetz et al., 2014). Consequently, exploring the factors that impact the users' adoption is significant to overcome the implementation challenges that may hinder the system success (Cresswell et al, 2013). Based on that, this study aims to explore patients' perceptions of the adoption of the online services of an EMR system.

User behavior toward new technology can be illustrated and expected by some theories and models such as the theory of reasoned action (Fishbein \& Ajzen \& 1975), the technology acceptance model (TAM) (Davis, 1989), the motivational model (Davis, 1989), the theory of planned behavior (Ajzen, 1991), a combined TAM and TPB (Taylor \& Todd, 1995), diffusion of innovation theory (Moore \& Benbasat, 1991; Rogers, 1962; Rogers, 2010), and the Unified Theory of Acceptance and Use of Technology (UTAUT) (Venkatesh et al., 2003).

In the context of HIS adoption and acceptance in SA, Mohamed \& El-Naif (2005) conducted a quantitative study in a military hospital in Riyadh to explore opinions and perceptions on the implementation of an EMR system. The sample included 105 physicians, 109 nurses, and 120 patients, who were surveyed on the current medical records department (MRD) and the quality of MRD services. However, only physicians were surveyed concerning EMRs. The study revealed that physicians at the time of the study had negative perceptions toward conversion from the current paper-based MRD to an EMR system. Only $31.3 \%$ of physicians believed it was time to move to EMRs, $68.7 \%$ believed that the existing MRD was more credible than EMRs, and more than $90 \%$ of the hospital physicians believed EMRs would add a burden on them, as EMRs require significant data entry from their side. Also, more than $80 \%$ of the sample physicians believed EMRs would decrease their productivity.

Another quantitative study by Bah et al. (2011) was conducted to measure EHR system adoption across the governmental hospitals located in the Eastern Province of SA. The study targeted the hospitals' IT managers. Out of 19 hospitals, only three hospitals used the same EHR system. The implemented system provides five main functionalities: chart review, decision support, order entry, documentation, and additional tools. For chart review functions, the system can obtain and review lab and radiology results, review progress notes, and monitor current and past medications and medication refills. The decision support functions of the system include receiving drug interaction and drug-allergy alerts when writing prescriptions, and highlighting test results that are out of normal range. Order entry functions enable the hospital staff to enter the lab, radiology, and pharmacy orders. Also, the EHR systems have some documentation functions that involve the systems' ability to create and maintain patient-related medical problem lists and common medication lists, identify patient-specific allergies, and document patient discharge instructions. Finally, the additional tools of the systems include managing patient referrals, automating coding of disease conditions, generating health statistics, and performing data backup and disaster recovery (Bah et al., 2011).

The Ministry of Health in SA has set many standards and policies for electronic health services to ensure effective and reliable implementation (Alkabba et al., 2012). Yet Alkabba and colleagues highlighted that the implemented systems were not capable of or not utilized to perform the following functionalities: creation and reviewing of scanned documents, communications, allowing hospitals' physicians to access patient records over the Internet when they are outside the hospital, and allowing patients to access their health records over the Internet (Bah et al., 2011). A similar study was carried about by Aldosari (2014) to examine the status of the EHR system in Riyadh as a sample of SA. Riyadh has a total of 30 hospitals; of these, 22 (16 governmental and 6 private) were surveyed to determine the rate, level, and determinants of EHR adoption. The study targeted project managers, medical directors, heads of IT departments, and EHR development teams. A total of 280 respondents completed the survey across all hospitals. The study found that for the rate of EHR adoption in Riyadh, of 22 hospitals, 19 had fully or partially adopted an EHR system. Of the hospitals included in the sample, $50 \%$ ( 11 hospitals) had implemented a fully functional EHR system, $36 \%$ ( 8 hospitals) were in the process of implementing an EHR system, and 14\% (3 hospitals) had not yet implemented a system.

Unlike the Eastern Province of SA (Bah et al., 2011), the 19 adopted hospitals implemented different EHR systems. Regarding the EHR system adoption level, three adoption phases were considered: implementation, maintenance, and improvement. For the implementation phase, the study found there was low preparation for the needed actions for the conversion from the current paperbased record system to an electronic one. For the maintenance phase, the major weakness was centered on software updates and maintaining and updating the CDSS. Concerning the improvement phase of EHR adoption, HIS communication and sharing is the main issue (Aldosari, 2014). With respect to EHR system adoption determinants, the study examined three primary determinants: hospital size, hospital ownership, and the EHR system development team. First, hospital size was reported to be positively related to the level of care complexity. Larger and tertiary hospitals had advanced EHR adoption. For the hospital ownership (public or private), 
the study findings showed that public hospitals were more advanced in the system implementation and maintenance phases than were private hospitals, which had better performance in the system improvement phase (Aldosari, 2014).

Additionally, a study on EHR adoption and barriers from nurses' perspective was conducted by El Mahalli (2015), which targeted 185 nurses in three public hospitals where the same EHR systems were implemented in the Eastern Province of SA. The applied systems provided some functionalities analogous to the ones in the study by Bah et al. (2011). The study revealed the underutilization of all EHR functionalities across the three hospitals. Also, similar to the findings of Bah et al. (2011), there was no utilization of any communication features; there were zero instances of using tools that "[allowed] patients to use the Internet to access parts of their health records" (El Mahalli, 2015).

For other forms of HISs, a study carried by Aldosari (2012) investigated radiology users' acceptance of a PACS in the radiology department at King Abdulaziz Medical City hospital in Riyadh, SA. The study used a modified TAM that contained three constructs: perceived usefulness (PU), perceived ease of use (PEOU), and change. In addition, a survey was conducted to validate the proposed model, and the targeted population (89 respondents) was radiology staff: consultants, radiologists, residents, technologists, and others who used the PACS in their work in the radiology department. The study concluded that all constructs in the proposed model (i.e., PU, PEU, and change) had a significant effect on radiology staff acceptance and the use of the PACS (Aldosari, 2012).

A recent study carried by Aljarboa et al. (2019) aimed to explore the factors of CDSS adoption in the context of the Saudi healthcare sector and to identify the possible use challenges of such technology. CDSS is a computerized mechanism that "provides clinicians with knowledge, intelligently filtered or presented at appropriate times, to enhance health and healthcare, and can be seen as an effective pathway to improve patient safety, providing, for instance, alerts for error reduction" (Zikos \& Delellis, 2018). The study targeted nine physicians from various specializations at different public and private hospitals and used qualified semi-structured interviews and applied some modifications to the UTAUT model constructs to fit both the healthcare and SA contexts. Two constructs were added to UTAUT: diagnostic accuracy and patient confidence. The study concluded that only five factors affected the physicians' intention to use CDSS: performance expectancy, effort expectancy, facilitating conditions, diagnostic accuracy, and patient confidence. The social influence determinant was reported as an insignificant factor (Aljarboa et al., 2019). Table 2 shows a summary of the studies mentioned above.

\section{Objective}

As per the literature, HISs contribute in improving healthcare productivity and cost-effectiveness, empowering patients by involving them in healthcare decision making and reducing medical errors (Zhang, 2002). On the other hand, there have been few investigations and studies regarding patients' adoption and acceptance of health IT solutions that require their inputs. Most adoption and acceptance studies focus on hospital staff, which includes physicians, nurses, medical directors, decision makers, laboratory technicians, and pharmacists (Alshahrani et al., 2019).

Considering this article's scope, which focuses on Saudi Arabia, the Ministry of Health in SA has prioritized the digitizing of health records and the development of electronic solutions in the healthcare context (Bah et al., 2011). The Ministry of Health has also made a variety of agreements to smooth the adoption and implementation of EMRs in primary healthcare centers. Nevertheless, the use of EMRs among Saudis is uncommon (Al-Sobhi et al., 2011). It is difficult to track the adoption of EHRs in SA due to limited publications in that area. A review of the 31 currently available publications on eHealth in Saudi Arabia showed that eHealth implementation and adoption is growing. On the other hand, the number of studies is limited and not growing at the same pace (Alsulame et al., 2016). Very few research studies have been conducted to quantify or measure the adoption of such technology (Aldosari, 2014), and none of these studies, to the author's knowledge, has focused on patients as among the HIS users. On this basis, this study aims to answer the following research question: What are the factors influencing patients to accept and use the online services of an EMR system?

\section{Methods}

This section shows the model proposed for the study and the constructs considered. The research is posited on the theoretical background of the TAM. Compared to other models that examine technology adoption, TAM is the most widely used in the literature (Ahlan \& Ahmad, 2014; Ma \& Liu, 2004). TAM is a theory that illustrates and helps to predict the impact of a system's usefulness 
and ease of use on users' intention to accept and use that technology (Davis, 1989). TAM was initially established to investigate the reasons why some users did not use and accept new technologies or systems when they were available to them (Holden \& Karsh, 2010). TAM has been broadly used in many HIS studies to depict healthcare providers' behavioral intention to use HISs. Moreover, many researchers have argued that TAM is more applicable than other technology acceptance theories in healthcare settings (Aggelidis \& Chatzoglou, 2009; Holden \& Karsh, 2010; Yarbrough \& Smith, 2007). According to a review by Holden and Karsh (2010), 16 of 20 studies concerning the implementation of health IT for patient care used the TAM or modified TAM, which predicts a significant portion of health IT acceptance and use. Although some studies used UTAUT model as it is the recent one and integrates constructs from different models, a study conducted recently revealed that applying the UTAUT to study the adoption of HIT in developing countries is inadequate and needs to be modified to fit the developing countries context (Bawack et al., 2018). In this study, TAM (Davis, 1989) is used as a theoretical foundation with one more construct from the UTAUT model (Venkatesh et al., 2003). Table 3 and Figure 1 demonstrate the proposed model.

\section{Study Setting and Participants}

The study was conducted in the Royal Commission Medical Center (RCMC) at Yanbu, SA. It is one of the main hospitals in Yanbu. RCMC is a public (governmental) hospital that was established in 1980 with a capacity of 68 beds; it currently has a capacity of over 400 beds.

RCMC has one main center, which is the Occupational Health Care Center, and seven polyclinics. RCMC received local and international accreditation from the Saudi Central Board for Accreditation of Health Care Institutions and the Joint Commission International. RCMC recently implemented an EMR system for managing patients' information, medical history, clinic visit appointments, examination appointments, and other functions. The system has many users, including patients. The targeted population includes RCMC patients. Random sampling was used, and a total of 116 patients responded to a questionnaire.

Considering the FCs construct of the UTAUT model (Venkatesh et al., 2003), an $d$ based on the four core determinants of TAM (PEOU, PU, ATT, and BI) (Davis, 1989), the following hypotheses were formulated:

Hypothesis 1 (H1): Facilitating conditions (e.g., information on the hospital website, skills, knowledge, and availability of technical support) will have a positive effect on the RCMC EMR system perceived ease of use.

Hypothesis 2 (H2): Perceived ease of use of the RCMC EMR system will have a positive effect on the perceived usefulness of the system.

Hypothesis 3 (H3): Perceived usefulness of the RCMC EMR system will have a positive effect on patients' attitudes toward the system.

Hypothesis 4 (H4): Patients' attitudes towards using the RCMC EMR system will have a positive effect on the intention to use the system.

\section{Data Collection}

A structured questionnaire was developed for this study to investigate patients' perceptions of using RCMC's electronic services. The questionnaire was online and written in Arabic and English. It included two sections where a combination of category and scaleranking questions were used. The response scale was a 5-point Likert-type scale, serving to measure the level of patients' agreement with questions and statements (1-Strongly disagree, 2-Disagree, 3-Neutral, 4-Agree, and 5-Strongly agree).

The first section of the questionnaire aimed to identify the patients' demographic characteristics using three questions inspired by Aldosari et al. (2018). The second part included 18 questions that were based on TAM user acceptance factors: PU, PEOU, ATT, and BI. Also, three questions were based on the FCs factor of the UTAUT model. Table 4 summarizes the items used.

All questions in the online questionnaire were set to be required for submission; therefore, there was no missing data among the 116 responses. For the sample characteristics, there was a higher proportion of female respondents (66\%) than male respondents (34\%). More than half of the participants belonged to the age group of 20-29 years old (57\%). The second-highest age group of the participants was $30-39(18 \%)$, followed by $40-49(10 \%)$, and patients who were $50-59$ and over 60 represented $15 \%$ of the sample. 
Among the participants who had experienced using computers, $28 \%$ had used computers for $6-10$ years, followed by $11-15$ years (22\%) and 16-20 years (19\%). Only a small minority (4\%) had used computers for $21-25$ years. Table 5 shows the study participants' characteristics.

\section{Results}

For the study model analysis, partial least squares-based structural equation modelling was performed for the data analysis using SmartPLS version 3.3.2. Two-step analysis was applied: measurement model and structural model analysis.

\section{Testing the Measurement Model}

Measurement model assessment aims to evaluate the reliability and validity of a proposed model's constructs, which include both reflective and formative measures. For the current study, reflective constructs, factor loadings, composite reliability (CR), and average variance extracted (AVE) were applied to evaluate the convergent validity. As Table 6 shows, all item loadings were at more than 0.7 , which exceeded the recommended value of 0.5 . The item composite reliability ranged from 0.889 to 0.957 , which exceeded the recommended value of 0.7 . For the AVE, the items' values ranged from 0.668 to 0.882 , which exceeded the recommended value of 0.5 .

After convergent validity, discriminant validity was tested, which included item cross-loading and the Fornell and Larcker (1981) criterion. For item cross-loading, as Table 7 shows, the loadings on constructs (written in bold) were higher than loadings with other constructs. For the inter-construct correlation test or Fornell and Larcker (1981) criterion, Table 8 shows that the construct square root of the AVE (written in bold) was higher than the correlation with other reflective constructs. Therefore, the reflective measurement model proved the convergent and discriminant validity.

For the formative measurement model, item weights and multicollinearity between indicators were tested to validate the formative constructs. First, the significance of item weights was evaluated. As shown in Table 9, there were some items with significant weight, such as PU1 and FC3, but they were not deleted. After that, multicollinearity was examined by the variance inflation factor (VIF). All items' VIFs (Table 9) were within the acceptable range, which is below 5 . Therefore, no items were deleted.

Table 10 and Figure 2 demonstrate the hypothesis testing that was used to assess the structural model. As shown, facilitating conditions ( $\beta=0.791, p<0.01)$ was positively related to perceived ease of use, therefore, $\mathrm{H} 1$ was supported. Perceived ease of use was significantly related to perceived usefulness $(\beta=0.755, p<0.01)$, which supported H2. Next is the relationship between perceived usefulness $(\beta=0.479, p<0.01)$ and attitude, which was also positively significant. Thus, H3 was supported. Similarly, the last relationship was verified, in which attitude $(\beta=0.652, p<0.01)$ was positively related to behavioral intention. Therefore, $\mathrm{H} 4$ was supported.

\section{Discussion}

This study was developed with the aim of exploring patients' acceptance of the electronic services provided by the RCMC EMR system in Saudi Arabia. A modified TAM was used to investigate patients' acceptance of the EMR system.

First, according to the results showed in the previous section, there was a positive correlation between FC and PEOU (H1). The path coefficient was positive and significant, which implies that a higher level of FCs reduces the difficulty of using such technology. It has been reported in many studies that FCs, such as IT support and training, comprise one of the crucial factors for users' acceptance in the context of healthcare (Aljarboa et al., 2019; Almaiman et al., 2014; El Mashalli, 2015). On the other hand, the impact of FCs on users' PEOU has not been hypothesized frequently in the literature. The finding of the present study goes hand in hand with a very recent study conducted by Tao et al. (2020) to investigate consumers' acceptance of healthcare wearable devices. The results of that study confirmed that FCs affect effort expectancy, which is equivalent to PEOU. In addition, studies by Li et al. (2019) and Tao et al. (2020) have revealed similar findings. Based on the findings of the current study, it is recommended that healthcare providers offer appropriate instructions on how to use a new technology or install an application for it on their websites. Also, IT support should be active and reachable to all patients. Second, PEOU and PU relationship. As reported in technology adoption literature, the foremost factors that affect users' willingness to adopt a system are the system usefulness and ease of use (Davis et al, 1989; Maillet et al, 2015; Venkatesh et al, 2003). There was a positive relationship between PEOU and PU (H2), which 
implies that healthcare technology, such as EMRs, would be perceived as more useful if it were easy and effortless to use. The same relationship was positive and significant in Tubaishat's (2017) study, which applied TAM to investigate nurses' use behavior of an EHR system. Similarly, many studies have confirmed this relationship from physicians' perspective, such as studies by Alsharo et al. (2019), Chen and Hsiao (2012), and Yarbrough and Smith (2007). In addition, a study conducted by Or et al. (2011) to examine home-care patients' acceptance of a web-based and interactive self-management technology revealed that PEOU did not directly affect the $\mathrm{BI}$, but it had a significant impact on PU. Another example is a study by Dutta et al. (2018), which examined individuals' intention to use one form of HIS, the personal health record. The findings showed that the PEOU-PU relationship was significant. Third, the current study showed that the relationship between PU and ATT was confirmed (H3). Many studies in the healthcare literature have reported the same significant relationship (Alsharo et al., 2019; Dutta et al., 2018; Holden \& Karsh, 2010). This indicates that if a hospital or healthcare provider wishes to attain better acceptance of healthcare technologies among the intended users, it is essential to ensure that such technology provides the advantages as expected and improves the healthcare efficiency and effectiveness. Therefore, it is recommended that healthcare providers employ different approaches to enhance the technology's PU, which would enhance patients' attitudes. This could include, for example, sending SMS messages, displaying presentations and short videos in waiting areas, and maintaining official accounts in social media and mobile technologies (Almaiman et al., 2014; Househ et al., 2010; Househ, 2011).

Last is the relationship between ATT and users' BI. Contrary to the findings of Ifinedo (2017), which did not confirm a relationship between nurses' attitudes and their behavioral intention to use HIS at work, in the present study the ATT and BI relationship was confirmed. The effect of physicians' ATT on BI has also been shown to be positively significant in other studies (Alsharo et al., 2019; Dutta et al., 2018).

\section{Conclusion}

This study aimed at studying patients' perceptions about accepting and using the online services of an EMR system in Saudi Arabia. The study proposed and tested a model that includes constructs from UTAUT and TAM models. The results revealed that facilitating conditions that involved patients' knowledge, skills, and the provided support by the hospital directly influenced the degree of system perceived ease of use, which in turn affected the EMR's perceived usefulness and directly affected patients' attitudes toward using the EMR. In addition, a positive effect was found between attitudes and the behavioral intention to use the EMR. The study analysis confirmed the validity of the proposed model in the context of patients' acceptance of healthcare technologies.

This study makes significant contributions to HIS research because it considers patients as among healthcare systems' users. Most healthcare adoption research has focused on physicians, nurses, and hospital administers. Patients have received little attention, especially in Saudi Arabia. To the best of the author's knowledge, this is the first study in the context of HIS/EMR adoption and acceptance from patients' perspectives in Saudi Arabia. On the other hand, the study has several limitations. First, it was limited to 116 patients who were located within the limited geographical context of Saudi Arabia. Different results might be seen in different countries and environments. Second, the proposed and tested model included only five constructs, which might be insufficient for understanding the use behavior of patients. Third, the patients' demographic characteristics were not considered in drawing the study findings. Last, the study questionnaire was only available online, which implied that patients who did not have access to the Internet were not included in the sample.

For future research, more studies are required to explore the factors that affect all HIS users' adoption to overcome the implementation challenges that may hinder the system's success. Investigation of patients' attitudes toward the adoption and acceptance of HIT/HIS is recommended (Aljarboa et al., 2019). In addition, according to Alkabba et al. (2012), the confidentiality of patients' information is ranked among the top three ethical issues for healthcare providers, patients, and their families in SA. Therefore, different constructs that are important to patients could be integrated with the model proposed in this study; these could include data privacy, data quality, system quality, system complexity, and social norms. Also, further research is needed on the impact of patients' demographic characteristics on their adoption behavior-characteristics such as gender, age, computer use experience, and education level.

\section{Abbreviations}


SA-Saudi Arabia; HIS- Hospital Information System; EHR- Electronic Health Record ; EMR- Electronic Medical Record; HIT- Health Information Technology; eHealth- Electronic health; CDSS- Clinical Decision Support System; ICT- Information and Communication Technologies; PHCCs- Primary Healthcare Centers; MRD- Medical Records Department ; PACS- Picture Archiving and Communication System; RCMC- Royal Commission Medical Center; TAM- Technology Acceptance Model; UTAUT- Unified Theory of Acceptance and Use of Technology; FC- Facilitating Conditions; PEOU- Perceived Ease of Use; PU- perceived Usefulness; ATTAttitude; BI- Behavioral Intention; CR- Composite Reliability; AVE- Average Variance Extracted; VIF- Variance Inflation Factor

\section{Declarations}

\section{Acknowledgments}

I would like to thank the patients who participated in this study for their valuable inputs.

\section{Author's contribution}

The author was the sole contributor to the entire study.

\section{Funding}

The author was the source of funds for this study.

\section{Availability of data and materials}

The data sets analyzed during the present study available from the corresponding author on reasonable request.

\section{Ethics approval and consent to participate}

Ethical approval was obtained from the research unit of the Yanbu University College for the research process.

The study participants, who are patients, were informed that their participation in the online survey was entirely voluntary, and they may choose to withdraw at any time. Participants answers are kept confidential, and no personally identifying information would be collected or recorded

\section{Consent for publication}

I agree to the publication of this manuscript.

\section{Competing interests}

The author declares that he has no competing interests.

Author Details

Department of Management Science, Yanabu University College, Yanbu, Saudi Arabia

\section{References}

1. Aggelidis, V. P., \& Chatzoglou, P. D. (2009) Using a modified technology acceptance model in hospitals. International Journal of Medical Informatics, 78(2), 115-126.

2. Ahlan, A., \& Ahmad, B. (2014). User acceptance of health information technology (HIT) in developing countries: A conceptual model. Procedia Technology, 16, 1287-1296.

3. Ajzen, I. (1991). The Theory of Planned Behavior. Organizational Behavior and Human Decision Processes, 50(2), $179-211$. https://doi.org/10.1016/0749-5978(91)90020-T

4. Aldosari, B. (2012). User acceptance of a picture archiving and communication system (PACS) in a Saudi Arabian hospital radiology department. BMC Medical Informatics and Decision Making, 12(1), 44. 
5. Aldosari, B. (2014). Rates, levels, and determinants of electronic health record system adoption: A study of hospitals in Riyadh, Saudi Arabia. International Journal of Medical Informatics, 83(5), 330-342. doi:10.1016/j.jimedinf.2014.01.006

6. Aldosari, B., Al-Mansour, S., Aldosari, H., \& Alanazi, A. (2018). Assessment of factors influencing nurses' acceptance of electronic medical record in a Saudi Arabia hospital. Informatics in Medicine Unlocked, 10, 82-88.

7. Aljarboa, S., Miah, S. J., \& Kerr, D. (2019). Perceptions of the adoption of clinical decision support systems in the Saudi healthcare sector. Proceedings of the 24th Asia-Pacific Decision Science Institute International Conference (APDSI), Brisbane, Australia, July 15-18, 2019.

8. Alkabba, A., Hussein, G., Albar, A., Bahnassy, A., \& Qadi, M. (2012). The major medical ethical challenges facing the public and healthcare providers in Saudi Arabia. Journal of Family and Community Medicine, 19(1), 1. doi:10.4103/2230-8229.94003

9. Almaiman, A., Bahkali, S., Alfrih, S., Househ, M., \& El-Metwally, A. (2014). The use of health information technology in Saudi primary healthcare centers. Studies in Health Technology and Informatics, 202, 209-212. doi:10.3233/978-1-61499-423-7-209

10. Alshahrani, A., Stewart, D., \& Maclure, K. (2019). A systematic review of the adoption and acceptance of eHealth in Saudi Arabia: Views of multiple stakeholders. International Journal of Medical Informatics, 128, 7-17.

11. Alsharo, M., Alnsour, Y., \& AlAiad, A. (2019). Exploring the change of attitude among healthcare professionals toward adopting a national health information system: The case of Jordan. International Journal of Business Information Systems, 1(1). doi:10.1504/ijbis.2020.10019466

12. Al-Sobhi, F., Weerakkody, V., \& El-Haddadeh, R. (2011). The relative importance of intermediaries in eGovernment adoption: A study of Saudi Arabia. Springer Berlin Heidelberg, 62-74. doi:10.1007/978-3-642-22878-0_6

13. Alsulame, K., Khalifa, M., \& Househ, M. (2016). E-health status in Saudi Arabia: A review of current literature. Health Policy and Technology, 5(2), 204-210. doi:10.1016/j.hlpt.2016.02.005

14. Anastassopoulos, G. C., Danielides, V., Konstantinidis, G., Karakos, A. S., \& Anagnostou, E. (2012). A user-centered, objectoriented methodology for developing health information systems: A clinical information system (CIS) example. Journal of Medical Systems, 36(2), 437-450.

15. Bagozzi, R. P., \& Yi, Y. (1988). On the evaluation of structural equation models. Journal of the Academy of Marketing Science, 16(1), 74-94.

16. Bah, S., Alharthi, H., El Mahalli, A. A., Jabali, A., Al-Qahtani, M., \& Al-kahtani, N. (2011). Annual survey on the level and extent of usage of electronic health records in government-related hospitals in Eastern Province, Saudi Arabia. Perspectives in health information management/AHIMA, American Health Information Management Association, 8(Fall).

17. Bawack, Ransome Epie, and Jean Robert Kala Kamdjoug (2018). Adequacy of UTAUT in clinician adoption of health information systems in developing countries: The case of Cameroon. International Journal of Medical Informatics, 109, 15-22.

18. Bozaykut, T., Kuyucu, E., \& Pinar, I. (2016). Investigating the antecedents of task-technology fit: a field study in Turkish private hospitals. International Journal of Business Information Systems, 22(4), 516-529.

19. Chaudhry, B., Wang, J., Wu, S., Maglione, M., Mojica, W., \& Roth, E. (2006). Systematic review: Impact of health information technology on quality, efficiency, and costs of medical care. Annals of Internal Medicine, 144(10), 742. doi:10.7326/0003-4819144-10-200605160-00125

20. Chen, R.-F., \& Hsiao, J.-L. (2012). An empirical study of physicians' acceptance of hospital information systems in Taiwan. Telemedicine and e-Health, 18(2), 120-125.

21. Cresswell, K. M., Bates, D. W. \& Sheikh, A. (2013) Ten key considerations for the successful implementation and adoption of large-scale health information technology. Journal of the American Medical Informatics Association, 20(e1), e9-e13.

22. Davis, F. D. (1989). Perceived usefulness, perceived ease of use, and user acceptance of information technology. MIS Quarterly, 13(3), 319-340. https://doi.org/10.2307/249008

23. Dutta, B., Peng, M.-H., \& Sun, S.-L. (2018). Modeling the adoption of personal health record (PHR) among individual: The effect of healthcare technology self-efficacy and gender concern. Libyan Journal of Medicine, 13(1).

24. El Mahalli, A. (2015). Electronic health records: Use and barriers among physicians in eastern province of Saudi Arabia. Saudi Journal for Health Sciences, 4(1), 32. 
25. Esmaeilzadeh, P., Sambasivan, M., Kumar, N. \& Nezakati, H. (2015) Adoption of clinical decision support systems in a developing country: Antecedents and outcomes of physician's threat to perceived professional autonomy. International Journal of Medical Informatics, 84(8), 548-560.

26. Fishbein, M., \& Ajzen, I. (1975). Belief, attitude, intention and behavior: An introduction to theory and research. Reading, MA: Addision-Wasely.

27. Fornell, C., \& Larcker, D. F. (1981). Evaluating structural equation models with unobservable variables and measurement error. Journal of Marketing Research, 18(1), 39-50.

28. Fraser, H., Biondich, P., Moodley, D., Choi, S., Mamlin, B. \& Szolovits, P. (2005) Implementing electronic medical record systems in developing countries. Journal of Innovation in Health Informatics, 13(2), 8395.

29. Geangu, I. P., Gârdan, D. A., Orzan, O. A., \& Oprescu, A. E. (2014). Medical services consumer protection in the context of eHealth development. Contemporary Readings in Law and Social Justice, 6(1), 473-482.

30. Gefen, D., Straub, D., \& Boudreau, M. C. (2000). Structural equation modeling and regression: Guidelines for research practice. Communications of the association for information systems, 4(1), 7.

31. Gell G., \& Gitter T. (2008) Hospital information system/electronic health record (HIS/HER) and clinical research. In P. J. J. Welfens \& E. Walther-Klaus (Eds.), Digital Excellence. Springer.

32. (n.d.). The electronic health record (EHR). https://www.himss.org/electronic-health-records

33. Holden, R. J., \& Karsh, B.-T. (2010) The technology acceptance model: Its past and its future in health care. Journal of Biomedical Informatics, 43(1), 159-172.

34. Househ, M. (2011). Sharing Sensitive Personal Health Information through Facebook: The Unintended Consequences. Studies in health technology and informatics, 169, 616-20.

35. Househ, M., Al-Tuwaijri, M., \& Al-Dosari, B. (2010). Establishing an electronic health center of research excellence (E-CoRE) within the Kingdom of Saudi Arabia. Journal of Health Informatics in Developing Countries, 4(1), 42-46.

36. Hu, P. J., Chau, P. Y., Sheng, O. R. L., \& Tam, K. Y. (1999). Examining the technology acceptance model using physician acceptance of telemedicine technology. Journal of Management Information Systems, 16(2), 91-112. doi:10.1080/07421222.1999.11518247

37. Hulland, J. (1999). Use of partial least squares (PLS) in strategic management research: A review of four recent studies. Strategic Management Journal, 20(2), 195-204.

38. Hunt, D. L., Haynes, R. B., Hanna, S. E., \& Smith, K. (1998). Effects of computer-based clinical decision support systems on physician performance and patient Outcomes: A systematic review, JAMA, 280(15), 1339-1346.

39. Ifinedo, P. (2017). Empirical study of Nova Scotia nurses' adoption of healthcare information systems: Implications for management and policy-making. International Journal of Health Policy and Management, 7(4), 317-327.

40. Ismail, A., Jamil, A., Rahman, A., Abu Bakar, J., Saad, N., \& Saadi, H. (2010). The implementation of hospital information system (HIS) in tertiary hospitals in Malaysia a qualitative study. Malaysian Journal of Public Health Medicine, 10(2), 16-24.

41. Khalifa, M. (2017). Perceived benefits of implementing and using hospital information systems and electronic medical records. In ICIMTH(pp. 165-168).

42. Kijsanayotin, B., Pannarunothai, S. \& Speedie, S. M. (2009) Factors influencing health information technology adoption in Thailand's community health centers: Applying the UTAUT model. International Journal of Medical Informatics, 78(6), 404416.

43. Kilsdonk E., Peute, L., Knijnenburg, S., \& Jaspers, M. (2010) Factors known to influence acceptance of clinical decision support systems. Studies in Health Technology and Informatics, 169, 150-154.

44. Lee, H., Ramayah, T., \& Zakaria, N. (2011). External factors in hospital information system (HIS) adoption model: A case on Malaysia. Journal of Medical Systems, 36(4), 2129-2140.

45. Li, J., Ma, Q., Chan, A. H., \& Man, S. (2019). Health monitoring through wearable technologies for older adults: Smart wearables acceptance model. Applied Ergonomics, 75, 162-169.

46. Ma, Q., \& Liu, L. (2004). The technology acceptance model: A meta analysis of empirical findings. Journal of Organizational and End User Computing (JOEUC), 16(1), 59-72. 
47. Maillet, É., Mathieu, L. \& Sicotte, C. (2015) Modeling factors explaining the acceptance, actual use and satisfaction of nurses using an Electronic Patient Record in acute care settings: An extension of the UTAUT. International Journal of Medical Informatics, 84(1), 36-47.

48. Menachemi, N., Burke, D., \& Ayers, D. (2004). Factors affecting the adoption of telemedicine-A multiple adopter perspective. Journal of Medical Systems, 28(6), 617-632.

49. Meyers, S. (2003). 'Concierge' medicine. Who really pays for gold standard access to doctors?. Trustee: The Journal for Hospital Governing Boards, 56(1), 4-12.

50. Mohamed, B. A., \& El-Naif, M. (2005). Physicians', nurses' and patients' perception with hospital medical records at a military hospital in Riyadh, Saudi Arabia. Journal of Family Community Medicine, 12(1), 49.

51. Moore, G. C., \& Benbasat, I. (1991). Development of an Instrument to Measure the Perceptions of Adopting an Information Technology Innovation. Information Systems Research, 2(3), 192-222. https://doi.org/10.1287/isre.2.3.192

52. Office of the National Coordinator for Health Information Technology. (n.d.). Glossary. https://www.healthit.gov/unintendedconsequences/content/glossary.html\#h

53. Oh, H., Jadad, A., Rizo, C., Enkin, M., Powell, J., \& Pagliari, C. (2005). What is eHealth (3): A systematic review of published definitions. Journal of Medical Internet Research, 7(1). doi:10.2196/jmir.7.1.e1

54. Or, C. K. L., Karsh, B.-T., Severtson, D. J., Burke, L. J., Brown, R. L., \& Brennan, P. F. (2011). Factors affecting home care patients acceptance of a web-based interactive self-management technology. Journal of the American Medical Informatics Association, 18(1), 51-59.

55. Rogers, C. R. (1962). The interpersonal relationship. Harvard educational review, 32(4), 416-429.

56. Rogers, E. M. (2010). Diffusion of innovations. Simon and Schuster.

57. Spetz, J., Gates, M. \& Jones, C. B. (2014) Internationally educated nurses in the United States: Their origins and roles. Nursing Outlook, 62(1), 8-15.

58. Tao, D., Wang, T., Wang, T., Zhang, T., Zhang, X., \& Qu, X. (2020). A systematic review and meta-analysis of user acceptance of consumer-oriented health information technologies. Computers in Human Behavior, 104, 106147.

59. Taylor, S., \& Todd, P. A. (1995). Understanding information technology usage: A test of competing models. Information Systems Research, 6, 144-176. https://doi.org/10.1287/isre.6.2.144

60. Tubaishat, A. (2017). Perceived usefulness and perceived ease of use of electronic health records among nurses: Application of technology acceptance model. Informatics for Health and Social Care, 43(4), 379-389.

61. Venkatesh, V., Morris, M., Davis, G., \& Davis, F. (2003). User acceptance of information technology: Toward a unified view. MIS Quarterly, 27, 425-478. https://doi.org/10.2307/30036540

62. Williams, F. \& Boren, S. (2008) The role of the electronic medical record (EMR) in care delivery development in developing countries: A systematic review. Journal of Innovation in Health Informatics, 16(2), 139-145.

63. Yarbrough, A. K., \& Smith, T. B. (2007) Technology acceptance among physicians: A new take on TAM. Medical Care Research and Review, 64(6), 650-672.

64. Zakaria, N., Affendi, S., \& Zakaria, N. (2010). Managing ICT in healthcare organization: culture, challenges, and issues of technology adoption and implementation. Health Information Systems: Concepts, Methodologies, Tools, and Applications (pp. 1357-1372). IGI Global.

65. Zhang, J. (2002). Medical error: Is the solution medical or cognitive?. Journal of the American Medical Informatics Association, 9(90061), 75S-77.

66. Zikos, D., \& Delellis, N. (2018). CDSS-RM: A clinical decision support system reference model. BMC Medical Research Methodology, 18(1), 137.

\section{Tables}




\section{Term Definition}

EHR / "The Electronic Health Record (EHR) is a longitudinal electronic record of patient health information generated by one EMR or more encounters in any care delivery setting. Included in this information are patient demographics, progress notes, problems, medications, vital signs, past medical history, immunizations, laboratory data and radiology reports. The EHR automates and streamlines the clinician's workflow. The EHR has the ability to generate a complete record of a clinical patient encounter-as well as supporting other care-related activities directly or indirectly via interfaceincluding evidence-based decision support, quality management, and outcomes reporting" (HIMSS, n.d.).

HIS A hospital information system (HIS) is defined as "a comprehensive, integrated information system designed to manage the administrative, financial and clinical aspects of a hospital. It aims to achieve the best possible support of patient care and administration by electronic data processing" (Ismail et al., 2010, p. 16-24). "It is an information system that performs the function of processing data, information and knowledge in the secondary and tertiary healthcare levels" (Lee et al., 2011, p. 2129-2140)

HIT Health information technology is "the application of information processing involving both computer hardware and software that deals with the storage, retrieval, sharing, and use of health care information, data, and knowledge for communication and decision making. Applications of health IT include the electronic health record (EHR), the personal health record, computerized physician order entry, and clinical decision support. In addition, health information exchanges are being developed to support sharing of information electronically among health care providers" (Office of the National Coordinator for Health Information Technology, n.d.)

eHealth eHealth refers to "all forms of electronic health care delivered via information and communication technology channels, ranging from informational, educational, and commercial, to direct services offered by Healthcare organizations, professionals, and consumers themselves" (Oh et al., 2005). E-health is "the use in the health sector, of digital data for clinical; educational and administrative purposes, both at the local site and at a distance" (Geangu et al., 2014, p. 473-482)

CDSS A clinical decision support system is "a computerized mechanism developed to assist healthcare providers make quality decisions regarding patient treatment and improve clinical management" (Hunt et al. 1998, p. 1339-1346). 
Table 2: Summary of Some HIS Studies in SA

\begin{tabular}{|c|c|c|c|c|c|c|c|}
\hline $\begin{array}{l}\text { Author, } \\
\text { Year }\end{array}$ & Objective & Country & Technology & $\begin{array}{l}\text { Study } \\
\text { Population }\end{array}$ & Sample Size & $\begin{array}{l}\text { Methodology/ } \\
\text { Theory }\end{array}$ & Key Findings \\
\hline $\begin{array}{l}\text { Mohamed } \\
\text { and El- } \\
\text { Naif } \\
\text { (2005) }\end{array}$ & $\begin{array}{l}\text { Evaluate } \\
\text { physicians', } \\
\text { nurses', and } \\
\text { patients' } \\
\text { perceptions } \\
\text { toward an EMR } \\
\text { system }\end{array}$ & $\begin{array}{l}\text { Saudi } \\
\text { Arabia }\end{array}$ & $\begin{array}{l}\text { EMR } \\
\text { system }\end{array}$ & $\begin{array}{l}\text { Randomly } \\
\text { selected } \\
\text { physicians, } \\
\text { nurses, and } \\
\text { patients at a } \\
\text { military } \\
\text { hospital in } \\
\text { Riyadh }\end{array}$ & $\begin{array}{l}\text { Randomly } \\
\text { selected } \\
\text { physicians } \\
(105), \text { nurses } \\
\text { (109), and } \\
\text { patients (120) }\end{array}$ & $\begin{array}{l}\text { Quantitative } \\
\text { (survey and } \\
\text { interview) }\end{array}$ & $\begin{array}{l}\text { - } \text { All } \\
\text { respondents } \\
\text { were surveyed } \\
\text { on the current } \\
\text { MRD and the } \\
\text { quality of MRD } \\
\text { services. } \\
\text { However, only } \\
\text { physicians were } \\
\text { surveyed } \\
\text { concerning } \\
\text { EMRs. } \\
\text { - Physicians } \\
\text { had negative } \\
\text { perceptions } \\
\text { toward } \\
\text { conversion from } \\
\text { current paper- } \\
\text { based MRD to } \\
\text { EMR system. } \\
\text { - Only } 31.3 \% \\
\text { of physicians } \\
\text { believed it was } \\
\text { time to move to } \\
\text { EMR system. } \\
\text { - } 68.7 \% \\
\text { believed that } \\
\text { existing MRD } \\
\text { was more } \\
\text { credible than } \\
\text { EMR. } \\
\text { - More than } \\
90 \% \text { of the } \\
\text { hospital } \\
\text { physicians } \\
\text { believed EMRs } \\
\text { would add } \\
\text { burden (data } \\
\text { entry). } \\
\text { - Moductivity. } \\
\text { physicians than } \\
\text { believed EMRs } \\
\text { theild decrease } \\
\text { product }\end{array}$ \\
\hline $\begin{array}{l}\text { Bah et al. } \\
(2011)\end{array}$ & $\begin{array}{l}\text { Measure and } \\
\text { explore the } \\
\text { level and extent } \\
\text { of EHR } \\
\text { systems in } \\
\text { governmental } \\
\text { hospitals } \\
\text { located in the } \\
\text { Eastern } \\
\text { Province of SA }\end{array}$ & $\begin{array}{l}\text { Saudi } \\
\text { Arabia }\end{array}$ & $\begin{array}{l}\text { EHR } \\
\text { system }\end{array}$ & $\begin{array}{l}\text { Hospital IT } \\
\text { managers }\end{array}$ & $\begin{array}{l}19 \text { govern- } \\
\text { mental } \\
\text { hospitals (19 } \\
\text { IT managers) }\end{array}$ & $\begin{array}{l}\text { Quantitative } \\
\text { (survey) }\end{array}$ & $\begin{array}{l}\text { - Out of } 19 \\
\text { hospitals, only } 3 \\
\text { used the same } \\
\text { EHR system. } \\
\text { The } \\
\text { implemented } \\
\text { system } \\
\text { provided } 5 \text { main } \\
\text { functionalities: } \\
\text { chart review, } \\
\text { decision } \\
\text { support, order } \\
\text { entry, } \\
\text { documentation, }\end{array}$ \\
\hline
\end{tabular}


and additional tools.

- Key challenges in

EHR system implementation were centered on resistance from doctors and nurses and lack of seriousness in inserting the needed inputs to use functions such as patient prescriptions, progress notes, and patient diagnosis.

$\begin{array}{llll}\begin{array}{ll}\text { Aldosari } \\ (2012)\end{array} & \begin{array}{l}\text { Assess } \\ \text { radiology users' } \\ \text { acceptance of }\end{array} & \begin{array}{l}\text { Saudi } \\ \text { Arabia }\end{array} & \text { HIS-PACS } \\ & \text { a PACS in the } & \\ & \text { radiology } \\ & \text { department }\end{array}$

$\begin{aligned} & \text { Consultants, } \\ & \text { radiologists, }\end{aligned}$ PACS
residents,
technologists,
and others
who used a
PACS in their
work in the
radiology
department

\section{- All \\ constructs in the proposed model (i.e., PU, PEU, and change) had a significant effect on radiology staff acceptance and use of PACS.}

- PU was the most influential factor, explaining 38\% of variation in the acceptance level.

\begin{tabular}{|c|c|c|c|c|c|c|}
\hline $\begin{array}{l}\text { Aldosari } \\
\text { (2014) }\end{array}$ & $\begin{array}{l}\text { Examine the } \\
\text { status of EHR } \\
\text { system } \\
\text { adoption in } \\
\text { terms of rate, } \\
\text { level, and } \\
\text { determinants, } \\
\text { in Riyadh as a } \\
\text { sample of }\end{array}$ & $\begin{array}{l}\text { Saudi } \\
\text { Arabia }\end{array}$ & $\begin{array}{l}\text { EHR } \\
\text { system }\end{array}$ & $\begin{array}{l}\text { Project } \\
\text { managers, } \\
\text { medical } \\
\text { directors, } \\
\text { heads of IT } \\
\text { departments, } \\
\text { EHR } \\
\text { development } \\
\text { teams }\end{array}$ & $\begin{array}{l}22 \text { hospitals } \\
\text { (16 } \\
\text { governmental, } \\
6 \text { private) } \\
\text { (280 } \\
\text { respondents) }\end{array}$ & $\begin{array}{l}\text { Quantitative } \\
\text { (survey) }\end{array}$ \\
\hline
\end{tabular}

- $\quad$ EHR adoption rate: out of 22 hospitals, 19 had fully or partially adopted an EHR system.

- EHR adoption levels: 3 adoption phases were examined: implementation, maintenance, and improvement. For the implementation phase, the core issue was the low preparation for the needed actions for digitizing the current paperbased record system. For the maintenance phase, the major weakness were software 
updates and

maintaining

and updating

(CDSS). For the

improvement

phase, HIS

communication

and sharing

was the main

issue.

- $\quad$ EHR

adoption

determinants: 3

primary

determinants

were explored:

hospital size,

hospital

ownership, and

EHR system

development

team. A positive

relationship

was reported

between

hospital size

and level of

care complexity.

For hospital

ownership

(public or

private), public

hospitals were

more advanced

in the system

implementation

and

maintenance

phases than

private

hospitals, but

not in the

improvement

phase.

\begin{tabular}{|c|c|c|c|c|c|}
\hline $\begin{array}{l}\text { Almaiman } \\
\text { et al. } \\
(2014)\end{array}$ & $\begin{array}{l}\text { Explore HIT } \\
\text { implementation } \\
\text { and identify the } \\
\text { main } \\
\text { associated } \\
\text { challenges with } \\
\text { using eHealth } \\
\text { in PHCCs in SA }\end{array}$ & $\begin{array}{l}\text { Saudi } \\
\text { Arabia }\end{array}$ & eHealth & $\begin{array}{l}\text { IT personnel } \\
\text { in the } \\
\text { National } \\
\text { Guards for } \\
\text { Health Affairs } \\
\text { and the } \\
\text { Ministry of } \\
\text { Health and } \\
\text { primary } \\
\text { healthcare } \\
\text { directors }\end{array}$ & $\begin{array}{l}14 \text { IT } \\
\text { personnel and } \\
11 \text { primary } \\
\text { healthcare } \\
\text { directors from } \\
5 \text { regions of } \\
\text { SA (Riyadh, } \\
\text { Hail, Arar, } \\
\text { Rafha, and } \\
\text { Najran) }\end{array}$ \\
\hline
\end{tabular}

Interviews
and academic
search

- HIT

adoption and use is growing in SA but is still in its early stage.

- Most PHCCs in SA maintain the required infrastructure for ICT and the needed IT resources.

- Low utilization of HISs and health electronic applications because of system failure, difficulty in using and navigating online system, 
negative

attitude toward

using the

systems, or

work overload.

- $\quad$ HIS at

PHCCS

contributed to

lower the no-

show rate and

improve service

quality.

- Critical

challenges for

HIS

implementation

in PHCCs:

disparity

implementation

of HIS in cities

and rural areas;

majority of

PHCCs in SA

use EMRs along

with paper-

based medical

records

- $\quad$ EMR

implementation

barriers include

policies,

organizational

technical

infrastructure,

users'

resistance to

change,

training, costs

and

confidentiality

of patient

information.

- Because

electronic

medical

services in

Saudi hospitals

are not

integrated at the

local or national

levels, there are

data quality

problems that

threaten data

security and

increase the

healthcare

costs.

\begin{tabular}{|c|c|c|c|c|c|c|c|}
\hline $\begin{array}{l}\text { El Mahalli } \\
(2015)\end{array}$ & $\begin{array}{l}\text { Investigate } \\
\text { nurses' } \\
\text { adoption and } \\
\text { barriers to use } \\
\text { EHRs }\end{array}$ & $\begin{array}{l}\text { Saudi } \\
\text { Arabia }\end{array}$ & EHRs & Nurses & $\begin{array}{l}185 \text { nurses } \\
\text { across three } \\
\text { public } \\
\text { hospitals in } \\
\text { the Eastern } \\
\text { Province of } \\
\text { SA }\end{array}$ & $\begin{array}{l}\text { Quantitative } \\
\text { (survey) }\end{array}$ & $\begin{array}{l}\otimes \text { The same } \\
\text { EHR system is } \\
\text { implemented in } \\
\text { the } 3 \text { hospitals. } \\
\bigotimes \text { The applied } \\
\text { EHRs provide } \\
\text { the following } \\
\text { functionalities: } \\
\text { chart review, }\end{array}$ \\
\hline
\end{tabular}


decision

support, order

entry,

documentation, communication with other

providers, and additional tools.

$\nabla$

Underutilization

of all EHR

functionalities

across the

systems at the

3 hospitals.

$\nabla$ No utilization

of any

communication

features.

$\checkmark$ No utilization of functionality

allowing

patients to access parts of their health

records online.

$\nabla$ Nurses' barriers to use

EHR system

(most to least

frequently cited): transient

loss of access

to records if

computer

crashes or

power fails, lack of continuous

training/support

from IT staff,

additional time

required for

data entry,

system hanging

up problem

complexity of

technology, and

lack of

customizability

to meet users'

needs.

\begin{tabular}{|c|c|c|c|c|c|c|c|}
\hline $\begin{array}{l}\text { Aljarboa } \\
\text { et al. } \\
\text { (2019) }\end{array}$ & $\begin{array}{l}\text { Determine the } \\
\text { factors that } \\
\text { affect the } \\
\text { adoption of } \\
\text { CDSSs in the } \\
\text { Saudi } \\
\text { healthcare } \\
\text { sector, and } \\
\text { identify the } \\
\text { challenges of } \\
\text { using such a } \\
\text { technology }\end{array}$ & $\begin{array}{l}\text { Saudi } \\
\text { Arabia }\end{array}$ & CDSS & $\begin{array}{l}\text { Physicians/ } \\
\text { doctors }\end{array}$ & 9 physicians & $\begin{array}{l}\text { Qualitative, } \\
\text { semi- } \\
\text { structured } \\
\text { interviews, } \\
\text { UTAUT }\end{array}$ & $\begin{array}{l}\text { Constructs were } \\
\text { added to } \\
\text { UTAUT: } \\
\text { diagnostic } \\
\text { accuracy and } \\
\text { patient } \\
\text { confidence. } \\
\text { O Only } 5 \text { factors } \\
\text { affected } \\
\text { physicians' } \\
\text { intention to use } \\
\text { CDSS: } \\
\text { performance } \\
\text { expectancy, } \\
\text { effort } \\
\text { expectancy, }\end{array}$ \\
\hline
\end{tabular}

Page 19/25 


facilitating
conditions,
diagnostic
accuracy, and
patient
confidence.
$\square$ Social
influence
determinant
was reported as
insignificant.
Q Studying
patients'
attitude toward
CDSS adoption
and acceptance
is
recommended.

Table 3: Proposed Model Constructs and Definitions

\begin{tabular}{|llll|}
\hline Construct & Definition & Reference \\
\hline $\begin{array}{l}\text { Perceived } \\
\text { usefulness (PU) }\end{array}$ & $\begin{array}{l}\text { "The degree to which a person believes that using a particular system would enhance } \\
\text { his or her job performance." }\end{array}$ & Davis (1989) \\
\hline $\begin{array}{l}\text { Perceived ease of } \\
\text { use (PEOU) }\end{array}$ & $\begin{array}{l}\text { "The degree to which a person believes that using a particular system would be free of } \\
\text { effort." }\end{array}$ & Davis (1989) \\
\hline $\begin{array}{l}\text { Attitude toward } \\
\text { behavior (ATT) }\end{array}$ & $\begin{array}{l}\text { "An individual's positive or negative feelings (evaluative effect) about performing the } \\
\text { target behavior." }\end{array}$ & $\begin{array}{l}\text { Fishbein \& } \\
\text { Ajzen (1975) }\end{array}$ \\
\hline $\begin{array}{l}\text { Behavioral } \\
\text { intention (BI) }\end{array}$ & "An individual's motivation or willingness to exert effort to perform the target behavior." & $\begin{array}{l}\text { Fishbein \& } \\
\text { Ajzen (1975) }\end{array}$ \\
\hline $\begin{array}{l}\text { Facilitating } \\
\text { conditions (FC) }\end{array}$ & $\begin{array}{l}\text { "The degree to which an individual believes that an organizational and technical } \\
\text { infrastructure exists to support the use of the system." }\end{array}$ & $\begin{array}{l}\text { Venkatesh et } \\
\text { al. (2003) }\end{array}$ \\
\hline
\end{tabular}


Table 4: Questionnaire Items

\begin{tabular}{|c|c|c|}
\hline Construct & Item & Code \\
\hline \multirow{4}{*}{$\begin{array}{l}\text { Perceived } \\
\text { Usefulness } \\
\text { (PU) }\end{array}$} & $\begin{array}{l}\text { The electronic health services offered in the website or the app address my needs (book } \\
\text { appointment, view lab/radiology results, medical reports, etc.). }\end{array}$ & PU1 \\
\hline & Using electronic health services saves me time. & PU2 \\
\hline & Using electronic health services makes it easier to get the hospital services. & PU3 \\
\hline & Overall, I find the electronic health services on the website or the app are useful. & PU4 \\
\hline \multirow{4}{*}{$\begin{array}{l}\text { Perceived Ease of } \\
\text { Use (PEOU) }\end{array}$} & Learning to use the electronic health services on the website or the app is easy for me. & PEOU1 \\
\hline & I find it easy to get the electronic health services to do what I want it to do. & PEOU2 \\
\hline & Using the electronic health services on the website or the app is clear and understandable. & PEOU3 \\
\hline & I find the electronic health services to be flexible to interact with. & PEOU4 \\
\hline \multirow[t]{3}{*}{$\begin{array}{l}\text { Facilitating } \\
\text { Conditions (FCs) }\end{array}$} & $\begin{array}{l}\text { I have the knowledge necessary to use the electronic health services offered on the website or } \\
\text { the app. }\end{array}$ & FC1 \\
\hline & $\begin{array}{l}\text { I think using the electronic health services in the website or the app fits well with the way I like to } \\
\text { get health services. }\end{array}$ & FC2 \\
\hline & $\begin{array}{l}\text { A specific person (or group) is available for assistance if I have problems using the electronic } \\
\text { health services offered in the website or the app. }\end{array}$ & FC3 \\
\hline \multirow[t]{4}{*}{ Attitude (ATT) } & Using electronic health services is a good idea. & ATT1 \\
\hline & I will be satisfied in using the electronic health services. & ATT2 \\
\hline & I think it is valuable to use electronic medical services. & ATT3 \\
\hline & Using electronic health services is favorable to me. & ATT4 \\
\hline \multirow{3}{*}{$\begin{array}{l}\text { Behavioral } \\
\text { Intention (BI) }\end{array}$} & I intend to use the electronic health services in the next months. & $\mathrm{BI} 1$ \\
\hline & I predict I would use the electronic health services in the next months. & $\mathrm{Bl} 2$ \\
\hline & I plan to use the electronic health services in the next months. & $\mathrm{BI} 3$ \\
\hline
\end{tabular}


Table 5: Study Participants' Characteristics

\begin{tabular}{|lll|}
\hline Characteristic & Frequency & Percentage $\%$ \\
\hline Gender $(\mathbf{N}=116)$ & & \\
\hline Male & 39 & $34 \%$ \\
\hline Female & 77 & $66 \%$ \\
\hline Age $($ Years $)(\mathbf{N}=116)$ & & \\
\hline $20-29$ & 66 & $57 \%$ \\
\hline $30-39$ & 21 & $18 \%$ \\
\hline $40-49$ & 12 & $10 \%$ \\
\hline $50-59$ & 10 & $9 \%$ \\
\hline $60+$ & 7 & $6 \%$ \\
\hline Duration of computer usage $($ Years $)(\mathbf{N}=116)$ & & \\
\hline Less than 5 years & 14 & $12 \%$ \\
\hline $6-10$ years & 32 & $28 \%$ \\
\hline $11-15$ years & 26 & $22 \%$ \\
\hline $16-20$ years & 22 & $19 \%$ \\
\hline $21-25 y e a r s$ & 5 & $4 \%$ \\
\hline more than 25 years & 17 & $15 \%$ \\
\hline
\end{tabular}


Table 6: Reflective Measurement Model

\begin{tabular}{|c|c|c|c|c|}
\hline Construct & Item & Loading $^{\text {b }}$ & AVE ${ }^{a, c}$ & $\mathrm{CR}^{\mathrm{a}, \mathrm{d}}$ \\
\hline Perceived & PEOU1 & 0.766 & 0.668 & 0.889 \\
\hline Ease of & PEOU2 & 0.869 & & \\
\hline \multirow[t]{2}{*}{ Use } & PEOU3 & 0.781 & & \\
\hline & PEOU4 & 0.849 & & \\
\hline \multirow[t]{4}{*}{ Attitude } & ATT1 & 0.909 & 0.814 & 0.946 \\
\hline & ATT2 & 0.854 & & \\
\hline & ATT3 & 0.927 & & \\
\hline & ATT4 & 0.917 & & \\
\hline Behavioral & $\mathrm{Bl} 1$ & 0.937 & 0.882 & 0.957 \\
\hline \multirow[t]{2}{*}{ Intention } & $\mathrm{BI} 2$ & 0.931 & & \\
\hline & $\mathrm{BI3}$ & 0.949 & & \\
\hline \multicolumn{5}{|c|}{ a. $\mathrm{CR}=$ composite reliability, $\mathrm{AVE}=$ average variance extracted } \\
\hline \multicolumn{5}{|c|}{ b. All item loadings > 0.5 indicate indicator reliability (Hulland, 1999) } \\
\hline \multicolumn{5}{|c|}{ c. All AVE > 0.5 indicates convergent reliability (Bagozzi \& Yi, 1988; Fornell \& Larcker (1981) } \\
\hline \multicolumn{5}{|c|}{ d. All CR > 0.7 indicates internal consistency (Gefen et al., 2000) } \\
\hline
\end{tabular}

Table 7: Discriminant Validity: Item

\begin{tabular}{|llll|}
\multicolumn{4}{c}{ Cross Loading } \\
\hline PEOU1 & $\mathbf{0 . 7 6 6}$ & 0.393 & 0.453 \\
\hline PEOU2 & $\mathbf{0 . 8 6 9}$ & 0.382 & 0.361 \\
\hline PEOU3 & $\mathbf{0 . 7 8 1}$ & 0.245 & 0.342 \\
\hline PEOU4 & $\mathbf{0 . 8 4 9}$ & 0.319 & 0.343 \\
\hline ATT1 & 0.402 & $\mathbf{0 . 9 0 9}$ & 0.569 \\
\hline ATT2 & 0.271 & $\mathbf{0 . 8 5 4}$ & 0.496 \\
\hline ATT3 & 0.359 & $\mathbf{0 . 9 2 7}$ & 0.657 \\
\hline ATT4 & 0.434 & $\mathbf{0 . 9 1 7}$ & 0.618 \\
\hline BI1 & 0.469 & 0.644 & $\mathbf{0 . 9 3 7}$ \\
\hline BI2 & 0.416 & 0.55 & $\mathbf{0 . 9 3 1}$ \\
\hline BI3 & 0.387 & 0.633 & $\mathbf{0 . 9 4 9}$ \\
\hline
\end{tabular}




\begin{tabular}{|c|c|c|c|}
\hline & PEOU & ATT & $\mathrm{BI}$ \\
\hline PEOU & 0.817 & & \\
\hline ATT & 0.411 & 0.902 & \\
\hline $\mathrm{BI}$ & 0.452 & 0.652 & 0.939 \\
\hline
\end{tabular}

Table 9: Formative Measurement Model

\begin{tabular}{|lllll|}
\hline Construct & Item & Weight & T-Value & VIF $^{*}$ \\
\hline Perceived & PU1 & -0.026 & 0.22 & 1.793 \\
\hline Usefulness & PU2 & 0.107 & 0.704 & 4.017 \\
& PU3 & 0.313 & 2.567 & 3.364 \\
\hline & PU4 & 0.681 & 6.434 & 2.619 \\
\hline Facilitating & FC1 & 0.268 & 2.839 & 1.143 \\
\hline Condition & FC2 & 0.788 & 8.154 & 1.458 \\
\hline & FC3 & 0.149 & 1.473 & 1.407 \\
\hline *VIF = variance inflation factor & & \\
\hline
\end{tabular}

Testing the Structural Model

Table 10: Hypothesis Testing

\begin{tabular}{|lllllll|}
\hline Hyp. & Relationship & Path coefficient & Std error & t-Value & P-Value $^{*}$ & Decision \\
\hline H1 & FC -> PEOU & 0.791 & 0.034 & 22.332 & $0.000^{* *}$ & Supported \\
\hline H2 & PEOU -> PU & 0.755 & 0.049 & 15.485 & $0.000^{* *}$ & Supported \\
\hline H3 & PU -> ATT & 0.479 & 0.105 & 4.548 & $0.000^{* *}$ & Supported \\
\hline H4 & ATT -> BI & 0.652 & 0.084 & 7.779 & $0.000^{* *}$ & Supported \\
\hline${ }^{*}$ Significance level $=0.05$ & & & & \\
\hline${ }^{* *} p \leq 0.01$ & & & & & \\
\hline
\end{tabular}

Figures 


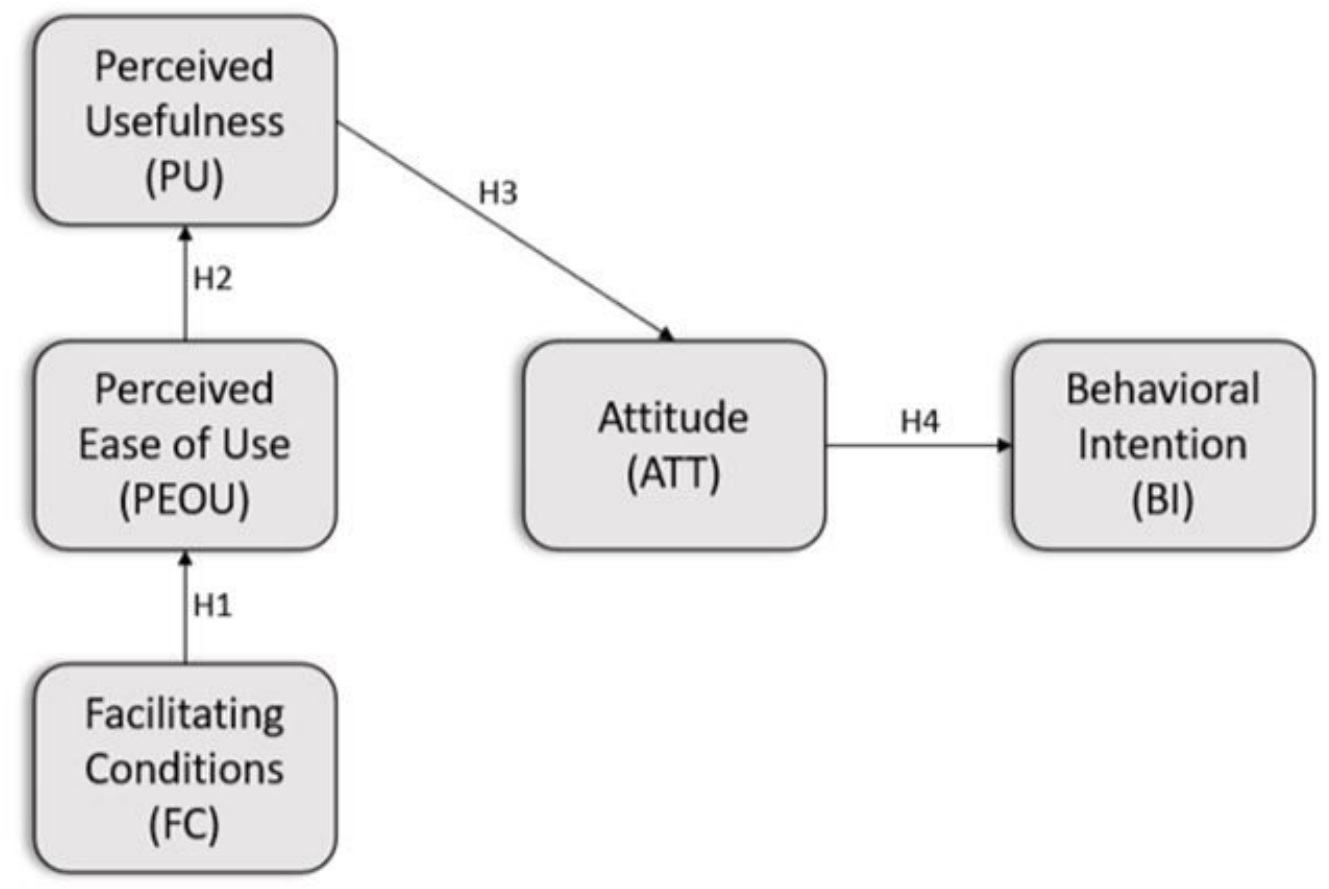

Figure 1

Proposed Model.

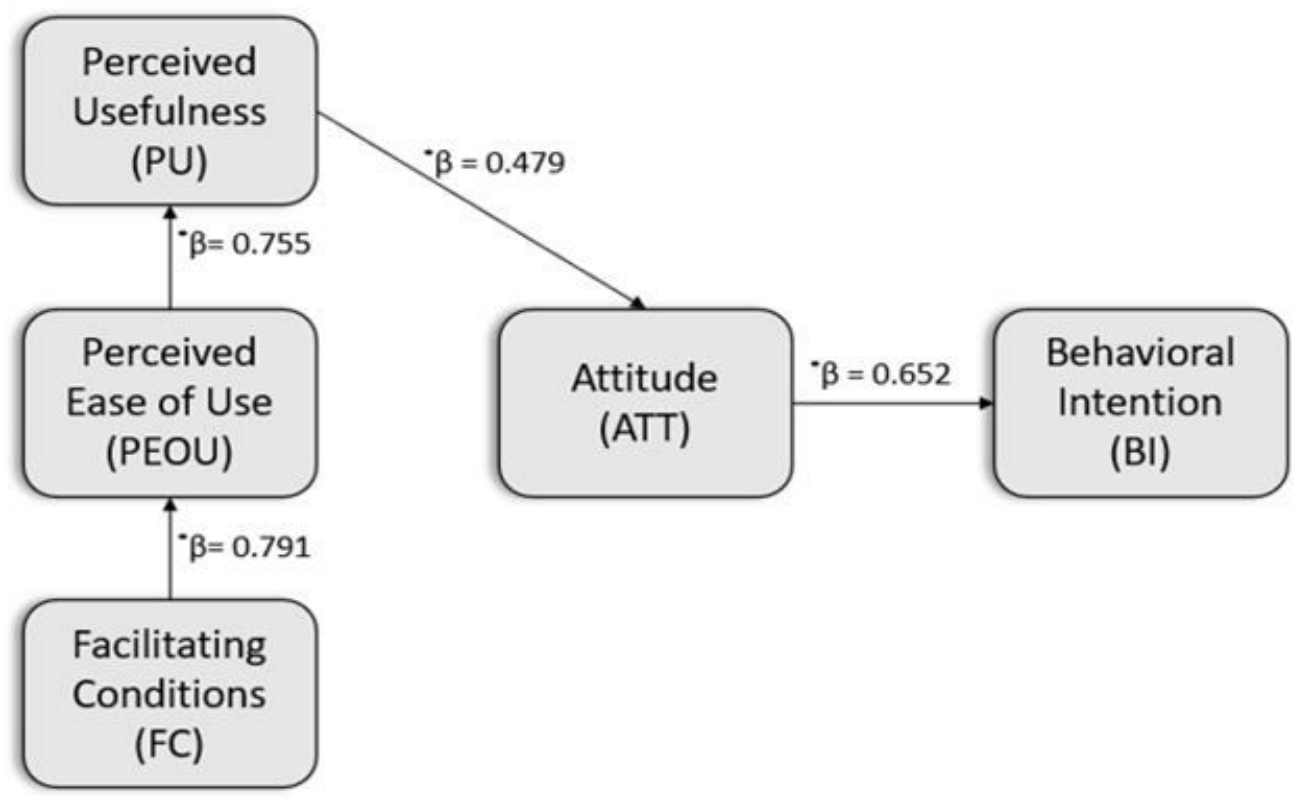

Figure 2

Results of the Structural Model. Note: ${ }^{*} \mathrm{p}<0.01$

\section{Supplementary Files}

This is a list of supplementary files associated with this preprint. Click to download.

- SupplementaryFile1Questionnaire.docx 